\title{
Bronchiolitis obliterans, bronchiectasis, and other sequelae of adenovirus type 21 infection in young children
}

\author{
D. M. O. BECROFT \\ From the Princess Mary Hospital for Children, Auckland, New Zealand
}

SYNOPSIS A remarkably high incidence of bronchiectasis and other pulmonary sequelae was $\$$ observed in young children affected during an epidemic of severe lower respiratory tract infections $\vec{N}$ apparently caused by adenovirus type 21 . The histopathological findings are described in four cases 0 in which one or both lungs were obtained for examination at intervals ranging from two months to $\lrcorner$ three years after the acute infections. Widespread bronchiolar obliteration (bronchiolitis obliterans) was a striking finding in all four. The severity of bronchial inflammation and of bronchiectasis was $\underset{\mathbb{O}}{\mathrm{O}}$ proportional to the time elapsed since the acute infections. Bronchiolar obliteration is a likely sequel of the necrotizing bronchiolitis which may occur during acute adenovirus infections. The role of ${ }^{\curvearrowright}$ bronchiolar obliteration in the pathogenesis of bronchiectasis and other chronic lung disease is $\vec{\varphi}$ discussed. Adenoviruses may be a major cause of post-infectious bronchiectasis in childhood.

The symptoms of bronchiectasis in childhood frequently date from an acute respiratory infection, and in four large series these infections were considered the likely initiating factor in $48 \%$ to $77 \%$ of cases (Field, 1949; Strang, 1956; Swierenga, 1957; Clark, 1963). However, pulmonary sequelae are rare in these common infections, and the exact aetiology of illnesses recalled as 'pneumonia', 'bronchitis', 'measles', or 'whooping cough' is often in doubt in retrospective studies. Therefore the contribution, individually and collectively, of the common bacterial and viral pathogens to subsequent chronic lung disease remains ill defined. The more precise diagnostic methods now available permit prospective studies, but few have been reported. An epidemic of adenovirus type 21 infection in Auckland during 1965 provided an opportunity for such a study. Over a six-month period 43 children aged 3 to 18 months were admitted to hospital with infections diagnosed initially as bronchiolitis, bronchitis, or bronchopneumonia. The distinctive feature of the epidemic was the protracted course of the illnesses in most children, waxing and waning over several weeks. Lang, Howden, Laws, and Burton (1969) have described the clinical, virological, and radiological findings in 25 of these patients in whom there was good evidence of advenovirus infection, this evidence including the isolation of adenovirus type Received for publication 9 June 1970.
21 from 20 cases. Only eight of the 25 patients considered by Lang et al (1969) appeared to recover: completely. One child died during the acute stages $\varnothing$ of the illness and $16(64 \%)$ had residual lung changes. $\overrightarrow{0}$ Five developed bronchiectasis. Of those with residual 3 lung changes, one died and two have had pneumonectomies. The pathological findings in these? three children and in a third fatality from the larger group of 43 cases will be described in this report. Widespread bronchiolar obliteration was found in 3 all four and the relationship of this change to the known acute effects of adenovirus infection and to the induction of further sequelae will be discussed.

\section{Case Reports}

All four infants were admitted to The Princess Mary N Hospital for Children within a three-week period in August 1965.

CASE 1

This 5-month-old Polynesian boy was admitted을 because of cough and wheeze for four days. He had had a morbilliform rash one week before. A diag-nosis of bronchiolitis, pneumonia, and mild otitis media was made on admission. Radiographs of the chest showed slight overinflation and increased? markings in both lung fields and consolidation of: the right lower lobe. His weight was at the 25 the 
percentile for age. The white blood count was $10,500 / \mathrm{cmm}$ (neutrophils $62 \%$ ) and there was a mild hypochromic anaemia. Staphylococcus pyogenes was cultured from the throat. He was treated with penicillin and then with cloxacillin and ampicillin. Fever subsided gradually over 10 days, but he continued to wheeze and oxygen was given intermittently for cyanosis. After four weeks, wheezing became exacerbated and he required oxygen continuously for several days. Radiographs at this time showed collapse of the lower lobe of the right lung and overinflation elsewhere. His condition fluctuated, but wheeze was always present and oxygen was required intermittently. Antispasmodics and antibiotics were continued with little effect. Sweat electrolyte levels were normal. Sixty-one days after his admission there was a further exacerbation of symptoms which, in contrast to earlier episodes, was accompanied by high fever. Further treatment with antibiotics and intravenous hydrocortisone had no effect and he died on the next day.

\section{Macroscopic findings at necropsy}

The pleural cavities were normal. The right lung weighed $120 \mathrm{~g}$, the left lung $110 \mathrm{~g}$. Both lungs were voluminous except for the right lower lobe which was collapsed and firm. In the remaining lobes pale emphysematous areas alternated with others which were firm and intensely congested or haemorrhagic. The bronchi in these lobes contained bloodstained fluid. The mucosa of bronchi throughout the lungs was thickened and congested but there was no bronchiectasis. Hilar lymph nodes were slightiy enlarged and fleshy. The heart weighed $50 \mathrm{~g}$. There was dilatation of the right ventricle and some hypertrophy of the ventricular wall. All other organs were normal.

\section{CASE 2}

This 9-month-old Maori boy was admitted with a three-day history of cough and wheezing. He had been in hospital with similar symptoms one month before when a diagnosis of acute wheezing bronchitis had been made, but he had appeared to recover completely and had remained well for three more weeks. A diagnosis of bronchopneumonia was made on the second admission. The radiographs of the chest showed overinflation of the lungs and interstitial inflammatory changes, but after a few days he developed clinical and radiological signs of a widespread patchy pneumonic consolidation in both lungs. His weight was at the 10th percentile. He had hypochromic anaemia with a haemoglobin of $6.9 \mathrm{~g} / 100 \mathrm{ml}$ and a white blood count of $7,200 / \mathrm{cmm}$ (68\% neutrophils). No bacterial pathogens were isolated from a throat swab. He was treated with cloxacillin and ampicillin and the pneumonia resolved slowly during the next three weeks. However, wheeze persisted and he was cyanosed at times. Continuous wheezing and overinflation of the lungs were the major clinical and radiological features of the remainder of his illness. He was afebrile most of the time and antibiotics, antispasmodics, and adrenal corticosteroids had no effect. Serum gamma globulin levels were normal. Five weeks after admission he developed a paroxysmal tachycardia and two weeks later there was a cardiac arrest. After he was resuscitated his respirations were assisted with intermittent positive pressure for one week and he had a tracheostomy. He did not regain consciousness and died in respiratory and cardiac failure four months after his second admission.

\section{Macroscopic findings at necropsy}

The pleural cavities were normal. The trachea below the tracheostomy and the main bronchi contained pus. The right lung weighed $130 \mathrm{~g}$, the left lung $100 \mathrm{~g}$. Both upper lobes were voluminous due to emphy-

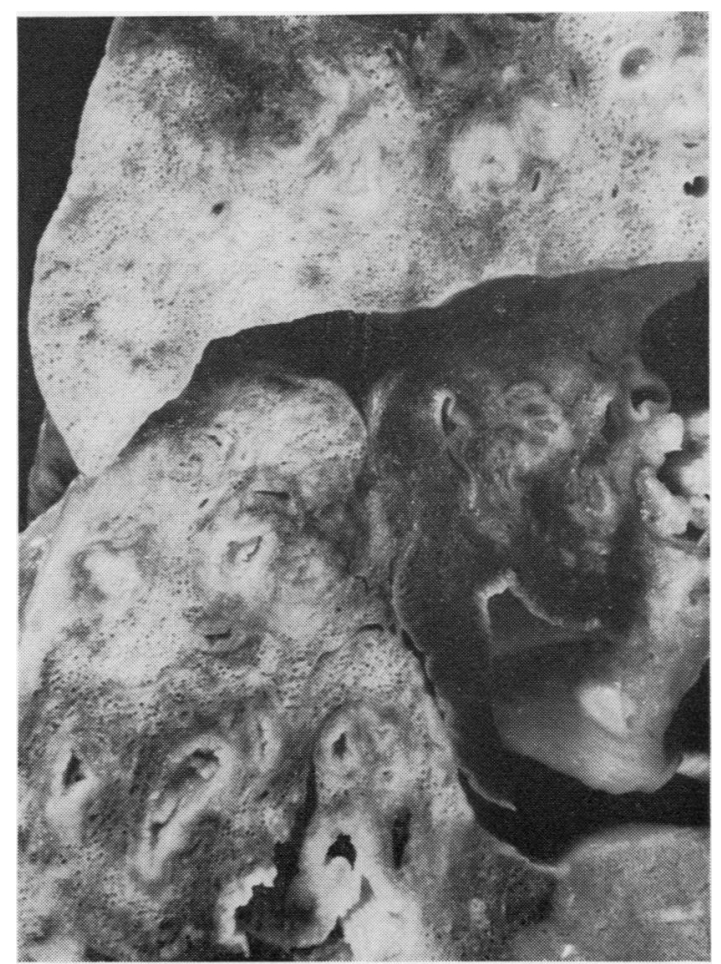

Fig. 1. The cut surface of the formalin-fixed right lung of case 2, four months after the acute infection. Thickening of bronchial walls, bronchiectasis, fibrosis, emphysema and $a$ bleb of bronchiolar origin are apparent. 
sema which included a few small blebs up to $4 \mathrm{~mm}$ in diameter (Fig. 1). There were small consolidated foci near the hilum of these lobes and more extensive areas of consolidation or collapse in the remaining lobes. Both lower lobes were reduced in volume and the bronchi were crowded together. Large and medium-sized bronchi in all lobes had thickened walls and irregular pus-filled lumina and there was obvious bronchiectasis in the partly collapsed lower lobes.

The heart weighed $100 \mathrm{~g}$ and there was hypertrophy of the right ventricular wall. The brain weighed only $680 \mathrm{~g}$ and showed extensive gliosis and cyst formation through the grey matter of the cerebral cortex and basal nuclei. The brain stem was normal as were other organs.

CASE 3

Nine days before admission this 11-month-old Caucasian boy developed a rash and was considered to have measles. The rash subsided, but was followed by fever, cough, and dyspnoea. On admission, ribs were retracted, and moist sounds were heard on auscultation all over the chest. A diagnosis of pneumonia was made. A radiograph of the chest showed abnormal markings compatible with peribronchial inflammatory changes. His weight was at the 3rd percentile and he had a mild hypochromic anaemia. The white blood count was $27,400 / \mathrm{cmm}$ (91\% neutrophils). No bacterial pathogens were isolated from a throat swab. He was treated with penicillin and chloramphenicol, but fever persisted and after three days his condition deteriorated, with severe wheezing and signs suggestive of right heart failure. Radiographs showed collapse-consolidation of the right lung with mediastinal displacement. He was treated with digoxin, cloxacillin, and streptomycin, and slowly improved. Fever subsided within a week of his admission but wheezing continued and there were residual changes in the radiographs of the re-expanded right lung when he was discharged after 26 days in hospital. He was readmitted only four days later because of a recurrence of fever and severe dyspnoea and wheezing. Radiographs of the chest showed generalized overinflation and an increase in the inflammatory changes in both lung fields. He was treated with cloxacillin and ampicillin and, although fever settled after three days, dyspnoea increased and he became cyanosed. Radiographs again showed collapse of the right lung and mediastinal displacement, but there was no reexpansion after removal of thick secretions at bronchoscopy. He improved slowly and was discharged again after 11 weeks in hospital, but had to be readmitted on several occasions because of exacerbations of the respiratory symptoms. Further

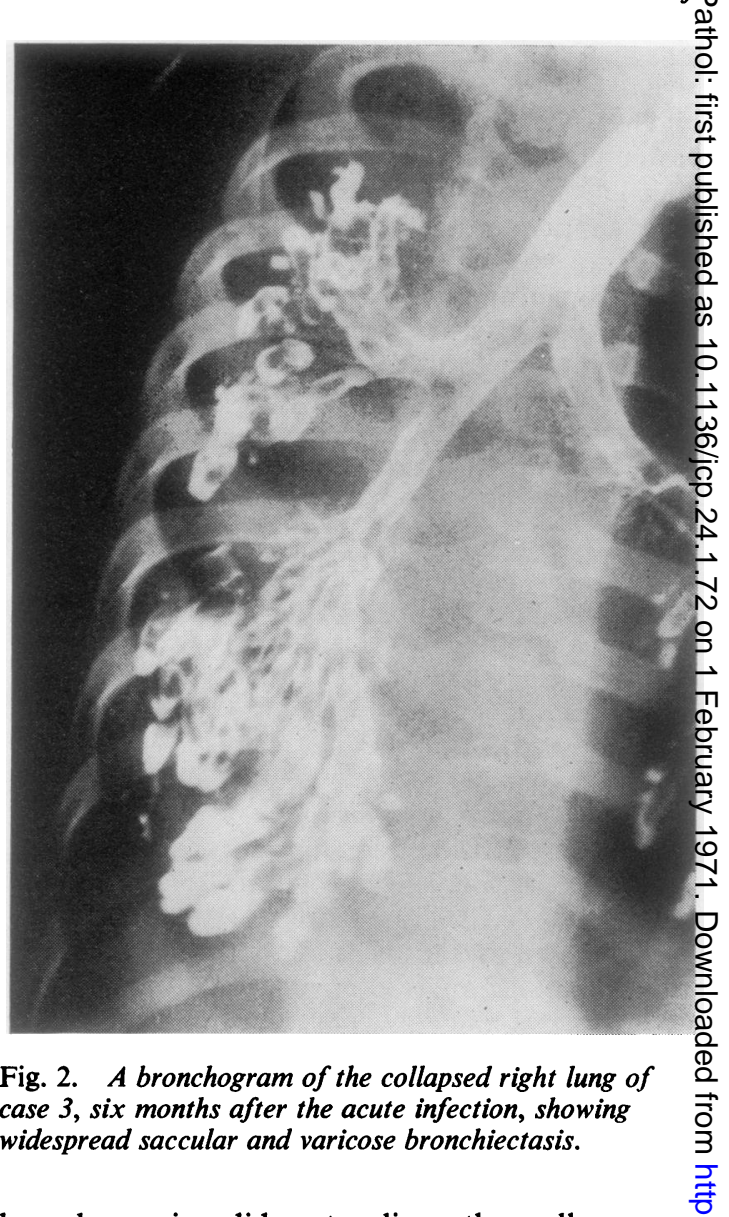

bronchoscopies did not relieve the collapse-con solidation of the right lung, and a bronchogram? performed six months after the onset of his illness showed extensive bronchiectasis of this lung (Fig. 2)? After one year a right pneumonectomy was per 8 formed at another hospital. After the pneumonec tomy he had one further hospital admission with ao respiratory infection, but then did not attend for follow up.

\section{Macroscopic findings}

The resected right lung was collapsed and markedi congested. The right main bronchus was normali but the major branches were obviously dilated particularly in the lower lobe where the subdivisions contained pus. The tracheobronchial lymph nodes were enlarged and fleshy.

CASE 4
This 10-month-old Polynesian boy had a history of cough, anorexia, and drowsiness for eight days. Fof three days he had been treated with tetracycline fo? 
bronchitis and pneumonia and he was admitted having had a convulsion. On admission he had signs of consolidation at the base of the right lung and radiographs confirmed the presence of bronchopneumonic changes in the right lung and in the left lower zone. His weight was at the 25 th percentile. He had a hypochromic anaemia, with a haemoglobin of $5.5 \mathrm{~g} / 100 \mathrm{ml}$. The white blood count was $11,400 /$ cmm (19\% neutrophils). No bacterial pathogens were isolated from a throat swab. Sweat, electrolyte, and serum gamma globulin levels were normal. He was treated with penicillin, cloxacillin, and ampicillin. The cerebrospinal fluid was normal, but symptoms of central nervous system disease were of major concern during the next three weeks. He had persistent fits and a paresis of the right arm from which he recovered slowly. As the consolidation cleared from the right lung the radiological appearances changed to overinflation on this side. There was intermittent wheezing and cyanosis. Then, four weeks after admission, radiographs showed collapse of the right lower lobe, followed two weeks later by collapse of the whole of the right lung. The lung did not expand after aspiration of secretions at bronchoscopy and tracheostomy. Bronchography, performed 12 weeks after admission, showed saccular bronchiectasis affecting all segments of the collapsed right lung and the posterior basal segment of the left lower lobe.

\section{CASE 5}

A child whose clinical course and radiological changes were described by Lang et al (1969) as their case 2 has had a right pneumonectomy nearly five years after the acute illness. The lung weighed $140 \mathrm{~g}$ and was examined in greater detail than was possible in previous cases. The lower lobe expanded to normal volume when inflated with air at a pressure of $40 \mathrm{~cm} \mathrm{H}_{2} \mathrm{O}$. The upper and middle lobes were atelectatic and could not be inflated. The possibility of a persisting virus infection was investigated by establishing fibroblast cultures from bronchial mucosa and alveolar tissue. Neither cell line showed cytopathic changes after six weeks in culture. Numerous sections of the lung were examined, many serially. There was severe fibrous thickening and chronic inflammation of the walls of small bronchi in all lobes. Most of the terminal bronchioles were completely obliterated and replaced by radiating fibrous scars accompanying smaller branches of the pulmonary arteries. As in the previous cases, many of these scars contained remnants of smooth muscle and elastic tissue. Although obliteration was equally severe in all lobes, most respiratory bronchioles, alveolar ducts, and alveoli in the lower lobe were well aerated, whereas the upper and middle lobes were atelectatic and hypoplastic. The radiological findings had suggested that this extensive obliteration had occurred during the first few weeks of the child's illness. There appears to have been a narrow margin between the degree of obliteration required to produce chronic atelectasis and that allowing sufficient collateral ventilation for aeration to be maintained.

He remained in hospital for many months having occasional exacerbations of respiratory symptoms. The right lung remained collapsed and a right pneumonectomy was performed three years later. He was well, but had signs persisting in the left chest, one year after the operation.

\section{Macroscopic findings}

The excised lung measured $11 \times 9 \times 5 \mathrm{~cm}$ in the inflated state. Large firm lymph nodes were present anterior to the entering bronchi, the largest $2 \mathrm{~cm}$ across. The bronchi in all lobes were considerably dilated and thick walled, the dilatation extending to the pleural surfaces (Fig. 3). Fibrous adhesions covered the pleural surface and there had been recent haemorrhage into the remaining lung parenchyma.

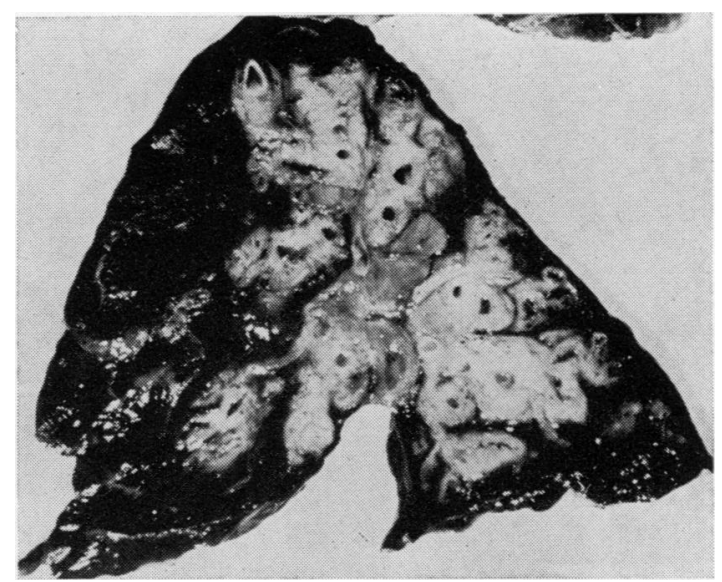

Fig. 3. Severe bronchiectasis and peribronchiul fibrosis in the right pneumonectomy specimen from case 4 three years after the acute infection.

\section{Histology}

Several blocks of tissue were taken from each lobe of the lungs of case 1 and one or more blocks from each lobe of case 2. Single blocks of tissue were available from the right middle and lower lobes of case 3 and from all three lobes of the right lung of case 4. Standard histological procedures were used 
for a variety of stains applied to sections from both paraffin-embedded and frozen material. Serial sections were examined from selected blocks of the lungs of cases 1 and 2.

\section{THE LOWER RESPIRATORY TRACTS \\ Large and medium-sized bronchi}

The thickening of the bronchial walls in each case was due to chronic inflammation and fibrosis which involved all layers to some extent, but ranged in severity from a predominantly mucosal change in case 1 to an advanced full-thickness disorganization typical of severe bronchiectasis in case 4 . The changes in cases 2 and 3 were of intermediate severity and there was a clear correlation between the amount of destructive change and the time since the initial infection. The lamina propria of the mucosa in each case was expanded by vascular fibrous connective tissue. Plasma cells and lymphocytes infiltrated this tissue, often heavily, but lymphoid follicles were seen in case 4 only. The mucosal surfaces of many large bronchi in cases 2 ,

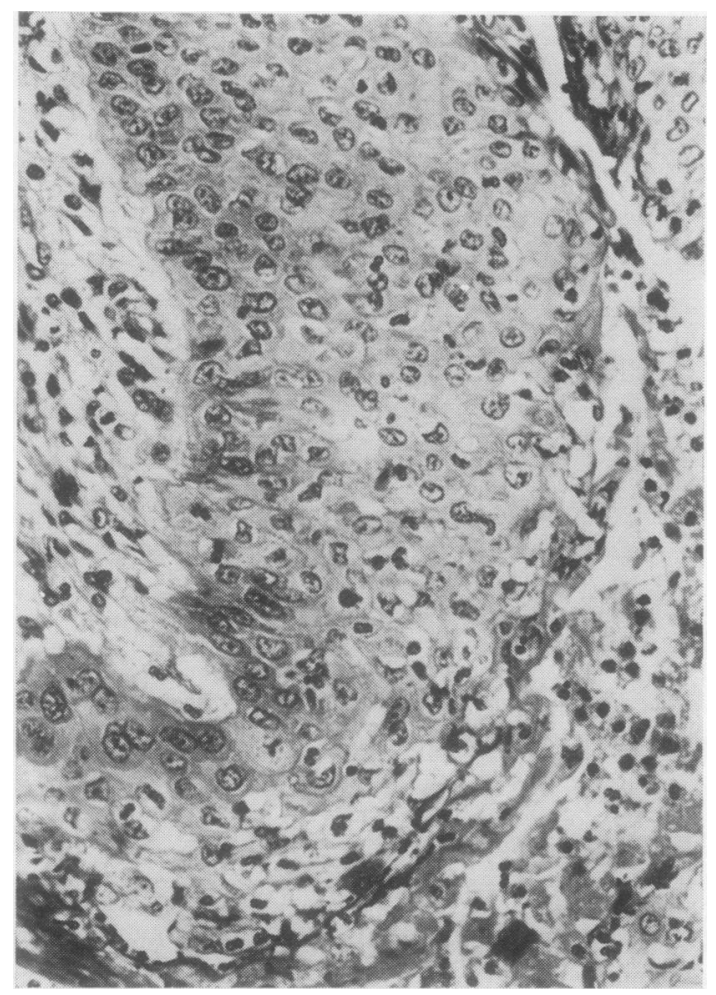

Fig. 4. Case 2. The proliferating epithelium lining a large pus-filled bronchus. The mitoses include a tri-aster. $H \& E \times 370$.
3 , and 4 were raised into a series of tall folds an papillary projections and many bronchial lumina. were filled with purulent exudate. The greater part of the bronchial epithelium was abnormal. The most? frequent change was simple hypertrophy with hypere plasia of goblet cells, but metaplasia into a manylayered, stratified, and otherwise undifferentiate $\phi$ epithelium was a feature of the mucosa of all large bronchi in case 2 . This epithelium also showed focat ulceration, intense mitotic activity, and a few atypical metaphases (Fig. 4). No viral inclusions: were detected in the bronchial epithelium, nor $a \vec{\omega}$ other levels of the respiratory tract in any of the four cases.

In case 1 the deeper layers of the bronchial wallis were infiltrated by lymphocytes and plasma cells; but there was little fibrosis. In cases 2 and 3 the cellular infiltration was more intense and there wao a variable fibrosis extending into the peribronchial tissues. Muscle and elastic tissue was disorganizedn in the walls of the more dilated bronchi but cartilage was unaffected. Cartilage, muscle, elastic tissue, an glands were largely destroyed in the walls of the greatly dilated bronchi of case 4 . Peribronchiato fibrosis and an inflammatory reaction, which included many lymphoid follicles, had incorporated much of the surrounding lung parenchyma in this case.

The loss of glands in case 4 was in keeping wit/ the severity of other changes in the bronchial wallso but in the other cases glandular involvement ap 2 peared disproportionately severe. This applied par $\overrightarrow{\vec{O}}$ ticularly in case 1 where many peripherally place $\Phi$ lobules were replaced by fibrous tissue containing chronic inflammatory cells, leaving only remnant? of acinar spaces lined by undifferentiated cuboidat cells.

\section{Small bronchi and bronchioles}

Obliteration or stenosis of bronchioles and smal bronchi was the most striking histological finding in these cases, particularly in cases 1 and 2 in which both lungs were available for full examination $\frac{D}{0}$ Obliterative changes were found in all sections from these cases and affected most of the smaller air pas $\widetilde{N}$ sages over large portions of all lobes. The appears ances illustrated in Fig. 5 were typical of the occluded air passages in cases 1,2 and 3 , in whick the mucosa was usually completely destroyed and the lumina filled with vascular fibrous tissue. Onlse the preservation of typically arranged smooth muscle and elastic fibres at the periphery allowed the ident $\mathrm{i}^{+}$ fication of many of these structures. Others contained clumps of epithelial cells or gland-like spaces Inflammatory cells, usually lymphocytes and plasma cells, were sparse. Serial sections showed that the 


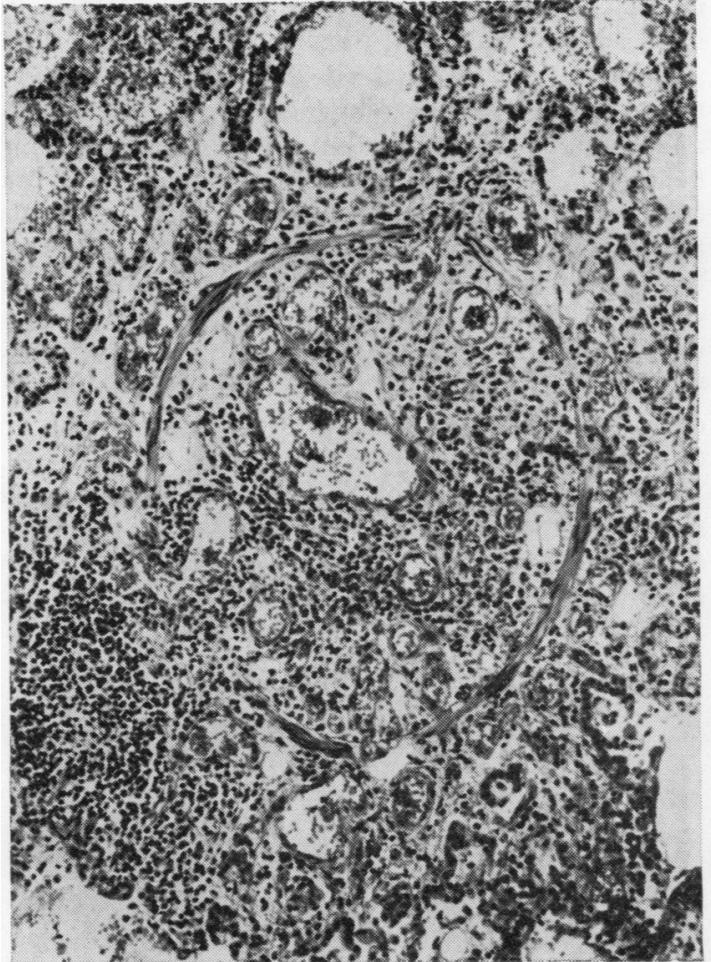

Fig. 5a

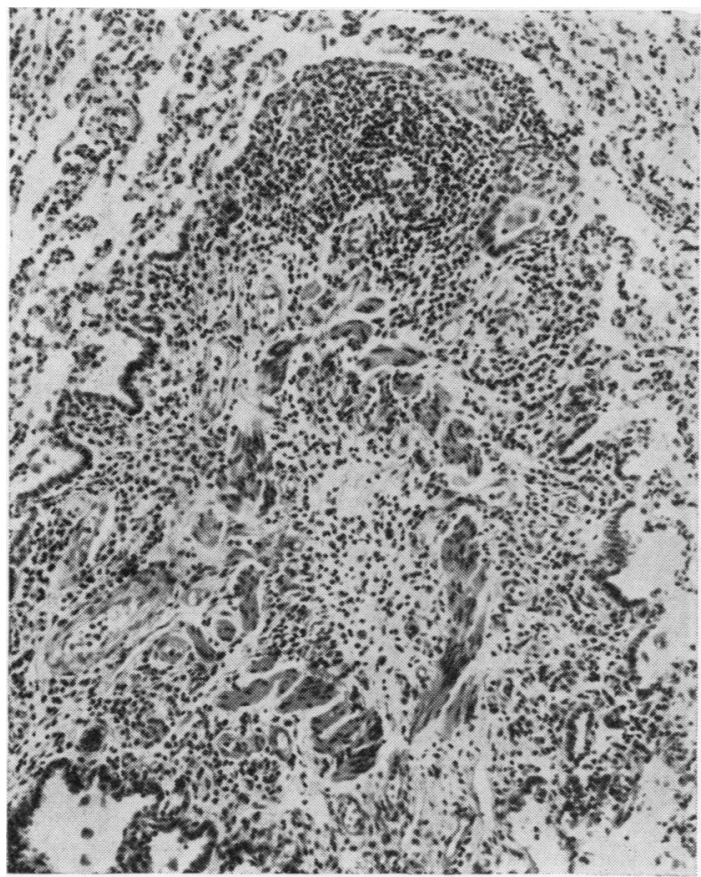

Fig. 5c

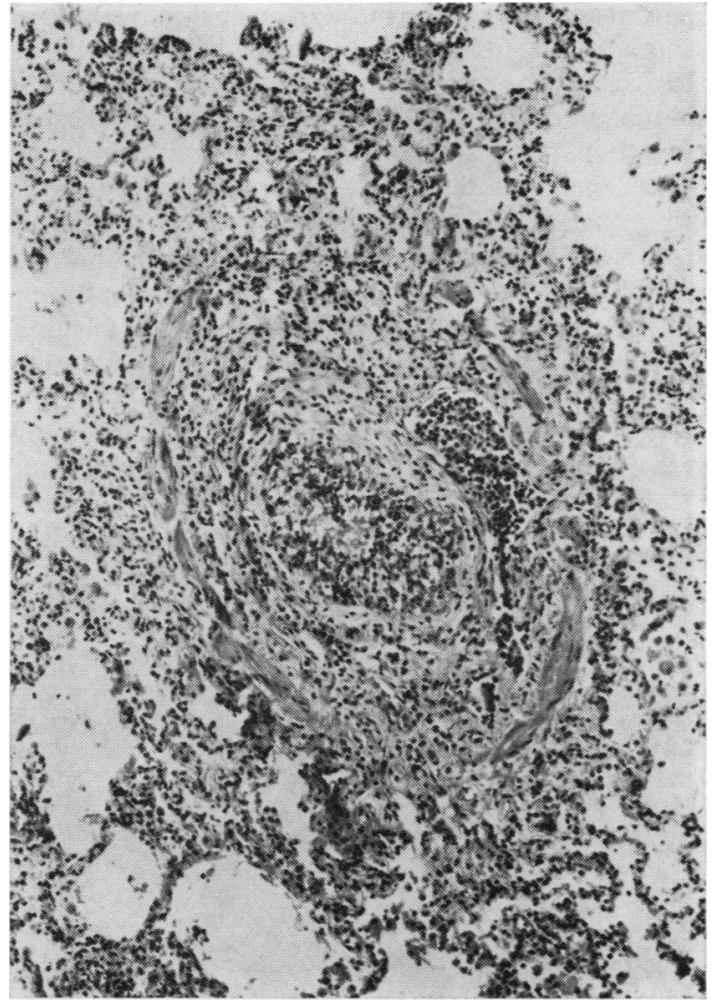

Fig. 5b

Fig. 5. Obliterative changes typical of the majority of bronchioles from (a) case 1, (b) case 2, and (c) case 3, two, four, and 12 months respectively after acute infections. A fragment of epithelium remains in (b) but otherwise the smooth muscle is the only identifying feature. $H \& E($ all $\times 120)$. 
transition from the patent proximal airway to the occluded segment was usually abrupt at a concave epithelial-covered surface. Some serial or longitudinal sections showed a sudden reduction in external diameter at the point of occlusion. Therefore, although the diameter of most obliterated air passages, as measured from the outer borders of the residual smooth muscle, was 150 to $500 \mu$ and never more than $1 \mathrm{~mm}$, presumably most had been larger before their obliteration. Nevertheless, the rarity of cartilage in the walls indicated that the maximum effect was on terminal bronchioles rather than on small bronchi (Fig. 6). The occlusion usually extended over a considerable length of the terminal bronchioles, but rarely included the respiratory bronchioles.

The bronchiolar lumina distal to the occlusions were dilated rather than collapsed and often had no

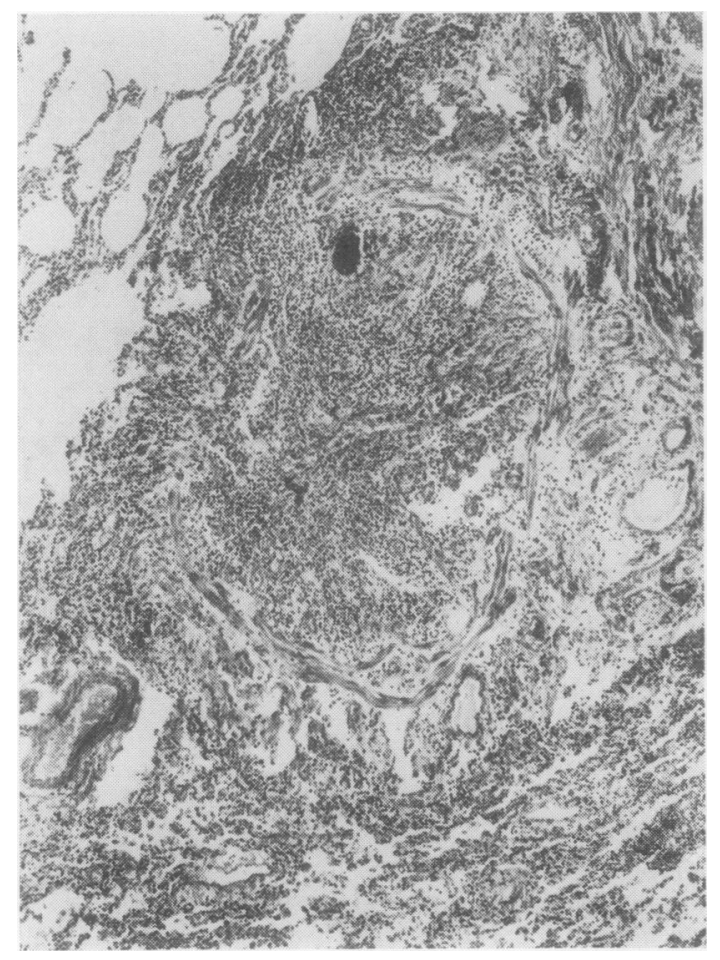

Fig. 6. Case 2. An obliterated small bronchus. In relation to the residual muscle layer there is, at the top, an epithelial fragment and a small cartilage plate and, above and at the left, remnants of bronchial glands. $H \& E .(\times 55)$. epithelial lining. Some of these distal segments werêّ filled with mucus and histiocytes, but most contained. air (Fig. 7). Some air-filled blebs of the type illus $\vec{z}$ trated in Fig. 1 had attenuated fibromuscular walls and no lining epithelium, but in serial sections couls be identified as respiratory bronchioles. In a few instances the occlusion consisted merely of a thin fibrous membrane separating the dilated distaP bronchiole from the epithelial-lined proximal airo space. A few small bronchi and larger bronchioles were stenosed rather than occluded, due either to $\dot{a}$ localized subepithelial fibrous thickening or tow diffuse chronic inflammatory changes similar to
those in the medium-sized bronchi.

No terminal bronchioles, or even remnants of these, could be identified in the severely bronchiec:tatic lung of case 4. All appeared to have been incorporated in the peribronchial fibrous and in

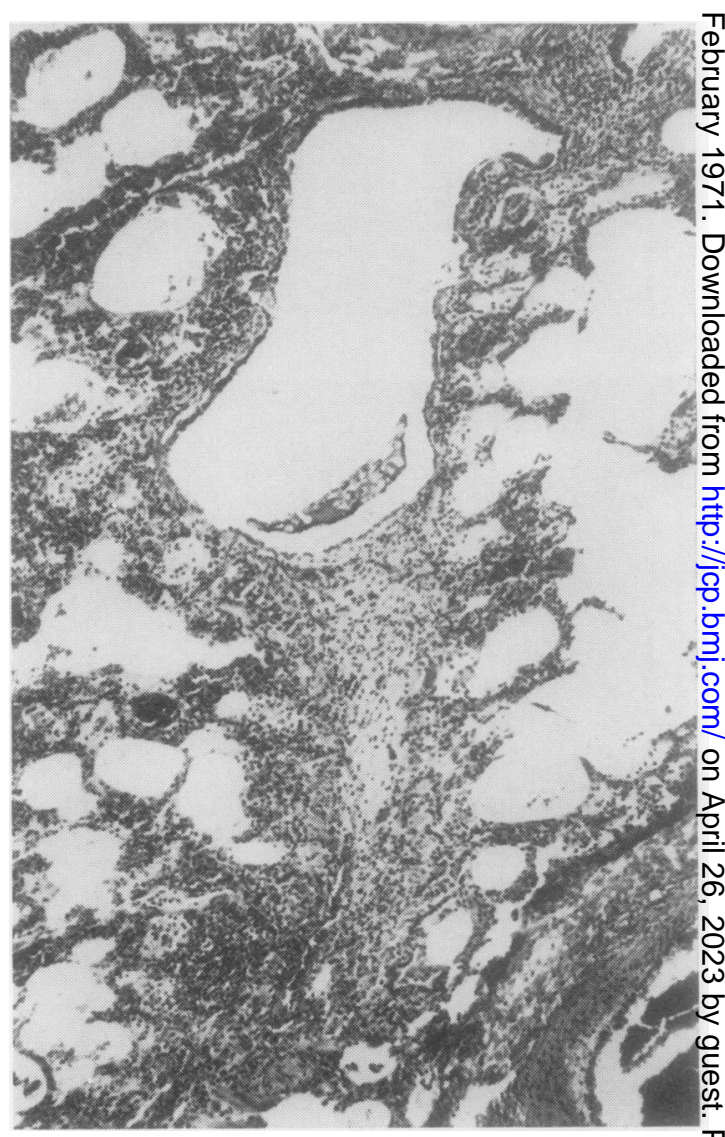

Fig. 7. Case 1. Dilatation of a respiratory bronchiole distal to an occluded segment cut obliquely at the foot of the photomicrograph. There is some mucus in the lumen. $H \& E(\times 60)$. 
flammatory tissue which replaced much of the lung and extended to near the pleural surfaces. Respiratory bronchioles, some mucus-filled, remained in the small amount of surviving alveolar tissue.

\section{Alveoli}

The greater part of the alveolar tissue was abnormal. Emphysema alternated with smaller areas of atelectasis and fibrosis in relation to the extensive bronchiolar obliteration in the lungs of cases 1 and 2 . Emphysema was particularly extensive in the upper lobes of cases 1 and 2 and was of obstructive type with little or no destruction of alveolar walls. The fibrotic areas in the lungs of case 2 , and more particularly in case 1 , often had a lobular distribution. Alveolar walls were diffusely thickened, the lining cells were cuboidal, and the alveolar lumens were filled with clumps of large macrophages many of which contained cholesterol. In case 1 both the fibrotic and non-fibrotic lung tissue showed focal infiltration by neutrophils, extensive fresh haemorrhage, and fibrinous exudation, changes which were taken as evidence for a terminal acute infection. In all cases the alveoli surrounding inflamed or occluded bronchioles and bronchi were lined by cuboidal cells. Apart from this change the alveolar tissue in the few sections examined from case 3 showed atelectasis only. The massive peribronchial fibrosis in case 4 included many alveolar remnants lined by cuboidal cells, while the residual alveolar tissue, situated mainly in the subpleural regions, was normal apart from a minor degree of collapse and recent haemorrhage.

\section{Vessels}

There was an endarteritis severely narrowing many small pulmonary arteries in case 2 and similar changes involving both pulmonary and bronchial arteries of case 4. Vessels in other cases were normal.

\section{Tracheo-bronchial lymph nodes}

In all cases these showed well developed, but nonspecific, reactive changes.

\section{OTHER ORGANS OF CASES 1 AND 2}

Apart from chronic inflammation and squamous metaplasia in the tracheal mucosa there were no changes of note in the upper respiratory tracts. The cortical grey matter of the brain of case 2 showed extensive gliosis and cyst formation consistent with anoxic injury. Other organs were unremarkable.

\section{Virology}

The methods of virological investigation and additional bacteriological and epidemiological data have already been presented by Lang et al (1969). The results of virological studies on the four cases of this report are presented in the Table. Type 21 adenoviruses were isolated from throat swabs taken from cases 2,3 , and 4 within a few days of their admission to hospital. The isolation from case 2 was at his second admission and, although relapses were common during the epidemic, the interval between the two admissions in this case was more than three weeks and the two were assumed to be unrelated. High titres of complement-fixing antibody to adenoviruses were demonstrated in convalescent sera from cases 2,3 , and 4 . These results were suggestive of recent infection, but an actual rise in titre from the acute phase was demonstrated in case 4 only. No other viruses were isolated, and the high titres of antibody to para-influenza virus type 3 in con-

\begin{tabular}{|c|c|c|c|c|c|c|c|c|c|c|c|c|c|c|c|}
\hline \multirow{3}{*}{$\begin{array}{l}\text { Case } \\
\text { No. }\end{array}$} & \multicolumn{3}{|c|}{ Virus Isolations } & \multicolumn{12}{|c|}{ Complement-fixing Antibodies (Reciprocals of Dilutions) } \\
\hline & \multirow[t]{2}{*}{ Specimen } & \multirow{2}{*}{$\begin{array}{l}\text { Day } \\
\text { Obtained }\end{array}$} & \multirow{2}{*}{$\begin{array}{l}\text { Virus } \\
\text { Isolated }\end{array}$} & \multicolumn{6}{|c|}{ Acute Serum } & \multicolumn{6}{|c|}{ Convalescent Serum } \\
\hline & & & & $\begin{array}{l}\text { Day } \\
\text { Obtained }\end{array}$ & $\begin{array}{l}\text { Adeno- } \\
\text { virus }\end{array}$ & $R S V$ & $P 1$ & $P 2$ & $P 3$ & $\begin{array}{l}\text { Day } \\
\text { Obtained }\end{array}$ & $\begin{array}{l}\text { Adeno- } \\
\text { virus }\end{array}$ & $R S V$ & $P 1$ & $P 2$ & $P 3$ \\
\hline 1 & $\begin{array}{l}\text { Lung } \\
\text { Faeces }\end{array}$ & $\begin{array}{l}62 \\
62\end{array}$ & - & 3 & $<16$ & $<16$ & $<8$ & $<8$ & $<16$ & NT & NT & $\mathbf{N T}$ & NT & $\mathbf{N T}$ & NT \\
\hline 2 & Throat swab & 5 & $\begin{array}{l}\text { Adenovirus } \\
\text { type } 21\end{array}$ & 6 & NT & $<16$ & $\mathbf{N T}$ & NT & NT & 34 & 128 & $<16$ & $<8$ & $<8$ & 128 \\
\hline \multirow[t]{2}{*}{3} & Throat swab & 1 & $\begin{array}{l}\text { Adenovirus } \\
\text { type } 21\end{array}$ & & & & & & & & & & & & \\
\hline & $\begin{array}{l}\text { Throat swab } \\
\text { Throat swab }\end{array}$ & $\begin{array}{r}31 \\
110\end{array}$ & $\begin{array}{l}\text { Adenovirus } \\
\text { type } 21\end{array}$ & NT & NT & NT & NT & NT & $\mathbf{N T}$ & 32 & 4096 & $>16$ & $>8$ & $>8$ & $>256$ \\
\hline 4 & Throat swab & 3 & $\begin{array}{l}\text { Adenovirus } \\
\text { type } 21\end{array}$ & 3 & $<16$ & $<16$ & $<8$ & $<8$ & $<16$ & & 512 & $<16$ & $<8$ & $<8$ & 128 \\
\hline
\end{tabular}

Table Results of virological studies

${ }^{1}$ Days after admission.

NT $=$ not tested.

PSV $=$ Respiratory syncytial virus.

R1 . P2, P3 = Parainfluenza viruses types 1,2 , and 3 respectively. 
valescent sera from these and other cases in the epidemic are unexplained.

\section{Discussion}

The pathological changes in these four children are considered to be the sequelae of infections by adenovirus type 21 which were acquired from two months to three years previously in individual cases. All were admitted to hospital at the height of the epidemic of adenovirus type 21 infection with clinical features resembling those of the other cases described by Lang et al (1969). Adenovirus type 21 was isolated and supporting serological evidence obtained in the three cases in which these investigations were carried out during the early part of the illnesses.

One feature common to the early clinical course of each case was that some radiological and clinical improvement had occurred before a serious impairment of ventilatory capacity became evident. All had severe wheezing and were cyanosed without oxygen at a time when fever had subsided and radiographs of the lungs showed hyperinflation but little collapse or consolidation. The persistence of these signs of obstructive lung disease in cases 1 and 2 until their deaths and for months in cases 3 and 4 correlates well with the dominant pathological finding of total or partial obliteration at bronchiolar and small bronchial level.

'Bronchiolitis obliterans', with a similar biphasic clinical course, has been described after exposure to toxic gases, after influenza, and other unspecified infections, and also in cases where no cause was apparent (Spencer, 1968). Laurent, Dalloz, and Nezelof (1966) reported the isolation of adenovirus type 5 from a 10-month-old child dying of bronchiolitis obliterans but, nevertheless, favoured the inhalation of some unknown toxin as the cause. The association with adenovirus infection cannot be easily dismissed in the present series of cases. Furthermore, the obliterative changes would be the sequelae predicted from what is known of the acute effects of adenovirus infections on the lower respiratory tract.

The histological findings in five cases of fatal infection by adenovirus type 7 in Auckland have already been described (Becroft, 1967). In this paper references were given to descriptions of a similar pathology found in more than 60 infants in whom death was attributed to infections by adenovirus of serotypes 7 or 3 , while later reports have added more cases and expanded the age range affected and the number of serotypes concerned (Levin, Dietrich, and Guillory, 1967; Angella and Connor, 1968; Steen-Johnsen, Örstavik, and Attramadal, 1969).
The characteristic features have been a combination. of necrotizing bronchitis, bronchiolitis, and pneu monia, necrosis of bronchial mucous glands, anf the presence of intranuclear inclusions in manye surviving cells. In the Auckland cases with type infection no respiratory epithelium had survived in some blocks of lung tissue and many bronchiola and bronchial lumina were filled with exudate fromis the ulcerated surfaces. The failure of reconstitution of ulcerated epithelium and the organization of exudate retained preferentially in smaller air pase sages wou!d lead to obliterative changes similar to those described above. Progression of this change? with cicatrization, episodic obstruction by retained secretions, and secondary infections could accountfor a fluctuating clinical course in the absence of persisting viral infection.

The necrosis which has been observed in the acute stages of adenovirus infection has not extendedi deeply to involve the cartilage or muscle layers. This can be correlated with the preservation of smootte muscle in the obliterated bronchioles of the cases? of this report and the absence of major destructive changes in the deeper layers of the bronchial walls. Obliteration of bronchial glands was dispropor:tionately severe in these cases and there is likelp correlation with the consistent finding of necrosis of these glands in the acute type 7 infections (Becroft 1967). A prior necrotizing pneumonia, resembling that found in the acute infections, is a possible cause of the alveolar fibrosis in cases 1 and 2 above, bu $\overrightarrow{\overrightarrow{6}}$ the fibrotic areas also had some features of obstruc 3 tive pneumonitis, including cholesterol accumula tion, and may have been secondary to bronchiolar. occlusion (Spencer, 1968).

Although the pathological findings in these cases appear a logical sequel to acute necrotizing changes. similar to those caused by other adenovirus sero: types, and although there is no reason to believes that type 21 should differ in its acute affects, there has been no direct demonstration of the latter. The few reports of adenovirus type 21 infections suggest that the virus resembles other adenovirus serotypes in usually causing only minor upper respiratory febrile, and ocular infections (Bell, Rota, and McComb, 1960; van der Veen and Dijkman, 1962) Lower respiratory tract infections have been de $\bar{\omega}$ scribed (van der Veen and Dijkman, 1962) and single fatal cases have been reported by Clarke, Corner? Gambier, Macrae, and Peacock (1964) and by Crandell, Dowdle, Holcomb, and Dahl (1968), but the extensive pneumonia in the former was not de응 scribed in detail and central nervous system disease predominated in the latter.

The occurrence of clinical and radiologicap sequelae in $60 \%$ of the surviving infants in the Auck 
land epidemic also appears to be exceptional for type 21 infection and for adenovirus infections generally. A few cases with persisting pulmonary lesions have been described (Lamy, Frézal, and Cohen-Solal, 1963; Clarke et al, 1964; SteenJohnsen et al, 1969), but sequelae were not mentioned in reports of other adenovirus epidemics (Sterner, 1962). The consistent finding of bronchiolar and bronchial obliteration in the pathological material from the Auckland epidemic suggests that this was of major importance in the pathogenesis of other pulmonary sequelae. The persistence of atelectasis, obstructive pneumonitis, or emphysema would be determined by the degree of bronchiolar obliteration and by the adequacy of collateral airways (McLean, 1958). In cases 1 and 2 emphysema was the more usual finding distal to the occluded airways, implying that collateral pathways were patent. Of the survivors, $10(40 \%)$ had radiographs showing permanently increased lung markings, with or without crowding of bronchi suggesting fibrosis or atelectasis. Three more, including cases 3 and 4 , had massive collapse of a lung persisting despite vigorous treatment, presumably because collateral airways were inadequate. The sequence of consolidation, followed by overinflation and then massive collapse of the right lung of case 4 , is believed to reflect progression of obliterative changes during resolution of the bronchopneumonia. Bronchiolar obliteration in infancy, with subsequent inhibition of normal development of the lung, has been proposed as a cause of McLeod's syndrome of unilateral radiolucency of the lung (Reid, Simon, Zorab, and Seidelin, 1967). Although radiographs of some survivors showed focal or generalized emphysema no typical examples of McLeod's syndrome were seen during the period of follow up.

Bronchiectasis was demonstrated at bronchography in six ${ }^{1}$ of the surviving cases at intervals of three months to one year after the acute infection, and was found at the necropsy on case 2 four months after the onset. Although bronchi in lobes known to be chronically atelectatic were most severely affected, non-atelectatic segments were also involved in all cases, and bilateral changes were demonstrated whenever both lungs were examined. The bronchiectasis was usually varicose or saccular and there was a consistent lack of filling of the periphery of the affected segments by contrast media, even in those examined early and showing only slight dilatation. This change, sometimes due to retained secretions, but usually indicating bronchial and bronchiolar obliteration, has been well documented in many radiological and pathological studies of bronchiectatic lungs (Reid, 1950; Culiner, 1963). The patho${ }^{1}$ One case has been added to the five listed by Lang et al (1969). logical findings in the present series of cases are considered to give support to the conclusion of Churchill (1949) that 'obliterative bronchitis and bronchiolitis with or without atelectasis may be significant in the development of certain types of bronchiectasis and not merely be a by-product of the pathologic process'. Bronchiolar obliteration could contribute to both factors considered by Spencer (1968) to be the main causes of bronchiectasis: first, to absorption, collapse, and fibrosis, and second, to inflammation, by predisposing anatomically and physiologically to the stagnation of secretions. Thus, in addition to the bronchiolar obliteration there was in case 1 , two months after the acute infection, only moderate bronchial inflammation; case 2 after four months had severe bronchial inflammation and early brorichiectasis; case 3 after one year had established bronchiectasis without gross destructive changes; and in case 4 after three years there was severe destructive bronchiectasis of follicular type in which the obliterative changes could easily be considered as secondary.

No opinion can be offered on the role of persisting viral infection in these cases. The virus was isolated from case 3 four months after his acute illness, but was not recovered from the lungs of case 1 after two months. The reactive changes in lymphoid tissue appeared non-specific, and although the atypical epithelial proliferation in case 2 had some resemblance to the virus-induced effect observed in the acute stages of adenovirus type 7 infection (Becroft, 1967), no viral inclusions were detected.

These cases provide strong evidence for an adenoviral aetiology of some cases of childhood bronchiectasis and for a pathogenesis based on an initial necrotizing bronchitis and bronchiolitis. The maximum incidence of the respiratory illnesses which have initiated symptoms in post-infectious bronchiectasis has, in most series, been in the first two years of life. Adenoviruses are an important cause of lower respiratory tract infections at this age, and of the other respiratory pathogens only influenza virus is recognized as causing epithelial necrosis of comparable extent. Adenoviruses may, therefore, be the major cause of post-infectious bronchiectasis, a possibility which has been suggested previously on the basis of serological studies by MacFarlane and Sommerville (1957) and Rytel, Connor, Welch, Kraybill, Edwards, Rosenbaum, Frank, and Miller (1964). Morbilliform rashes and other exanthemata, a pertussis-like syndrome, and a simultaneous infection with measles virus have all been described in association with adenovirus infection (Chany, Lépine, Lelong, Le-Tan-Vinh, Satgé, and Virat, 1958; St. Geme and Prince, 1966; Collier, Connor, and Irving, 1966; Lang et al, 1969). Conse- 
quently, adenoviruses have also to be considered as the possible aetiological agents in cases of bronchiectasis developing after apparent measles or whooping cough. Clearly, only prospective studies based on accurate initial diagnoses can give reliable information on the infectious causes of bronchiectasis.

I am grateful to Dr Grahame Fox, Dr Alice Bush, and Dr Ruthven Lang for permission to publish details of cases in their care; to Dr J. F. Burton for the results of virological studies; to Dr F. H. Sims for access to the descriptions of the surgical specimens and to the histological material from cases 3 and 4; to Dr Geoffrey Dodd for reviewing radiographs; and to Mr A. D. Fraser and Mr R. J. Patterson for expert assistance with photographic and histological procedures respectively.

\section{References}

Angella, J. J., and Connor, J. D. (1968). Neonatal infection caused by adenovirus type 7. J. Pediat., 72, 474-478.

Becroft, D. M. O. (1967). Histopathology of fatal adenovirus infection of the respiratory tract in young children. J. clin. Path., 20, $561-569$.

Bell, S. D., Jr., Rota, T. R., and McComb, D. E. (1960). Adenovirus isolated from Saudi Arabia. III. Six new serotypes. Amer. J. trop. Med. Hyg., 9, 523-526.

Clark, N. S. (1963). Bronchiectasis in childhood. Brit. med. J., 1, 80-88.

Clarke, S. K. R., Corner, B. D., Gambier, D. M., Macrae, J., and Peacock, D. B. (1964). Viruses associated with acute respiratory infections. Brit. med. J., 1, 1536-1539.

Chany, C., Lépine, P., Lelong, M., Le-Tan-Vinh, Satgé, P., and Virat, J. (1958). Severe and fatal pneumonia in infants and young children associated with adenovirus infections. Amer. J. Hyg., 67, 367-378.

Churchill, E. D. (1949). The segmental and lobular physiology and pathology of the lung. J. thorac. Surg., 18, 279-293.

Collier, A. M., Connor, J. D., and Irving, W. R. Jr. (1966). Generalised type 5 adenovirus infection associated with the pertussis syndrome. J. Pediat., 69, 1073-1078.
Crandell, R. A., Dowdle, W. R., Holcomb, T. M., and Dahl, E. $\overrightarrow{\widetilde{Q}}$. (1968). A fatal illness associated with two viruses: an intetmediate adenovirus type $(21-16)$ and influenza A. J. Pediat. , 467-473.

Culiner, M. M. (1963). Obliterative bronchitis and bronchiolitis with bronchiectasis. Dis. Chest., 44, 351-361.

Field, C. E. (1949). Bronchiectasis in childhood. I. Clinical survey 160 cases. Pediatrics, 4, 21-46.

Lamy, M., Frézal, J., and Cohen-Solal, J. (1963). Pneumopat chronique associée à une infection par adenovirus. Arch. fraळ Pediat., 20, 612-620.

Lang, W. R., Howden, C. W., Laws, J., and Burton, J. F. (1969). Bronchopneumonia with serious sequelae in children wh evidence of adenovirus type 21 infection. Brit. med.J., 1, 73-79.

Laurent, M., Dalloz, J. C., and Nezelof, C. (1966). La bronchiolite oblitérante: à propos d'un cas frappant un neurrisson de 90 mois. Arch. Anat. Path., 14, 253-259.

Levin, S., Dietrich, J., and Guillory, J. (1967). Fatal nonbacter(a) pneumonia associated with adenovirus type 4. J. Amer. met. Ass., 201, 975-977.

Macfarlane, P. S., and Sommerville, R. G. (1957). Non-tuberculous juvenile bronchiectasis: a virus disease? Lancet, 1, 770-771:

McLean, K. H. (1958). The pathogenesis of pulmonary emphysenpo Amer. J. Med., 25, 62-74.

Reid, L.McA. (1950). Reduction in bronchial subdivision in bronchiętasis. Thorax, 5, 233-247.

Reid, L., Simon, G., Zorab, P. A., and Seidelin, R. (1967). The devet opment of unilateral hypertransradiancy of the lung. Brit. $\mathbb{d}$. Dis. Chest, 61, 190-192.

Rytel, M. W., Conner, G. H., Welch, C. C., Kraybill, W. H., Edwarf, E. A., Rosenbaum, M. J., Frank, P. F., and Miller, L. F. (1964. Infectious agents associated with cylindrical bronchiectasis. Dis. Chest, 46, 23-28.

St. Geme, J. W., Jr., and Prince, J. T. (1966). Mixed systemic vikus $\$$ infection: a postulate for alteration of host resistance to adenovirus infection. J. Pediat., 69, 653-655.

Spencer, H. (1968). Pathology of the Lung, 2nd ed. Pergamon Pres, Oxford.

Steen-Johnsen, J., Örstavik, I., and Attramadal, A. (1969). Sever illnesses due to adenovirus type 7 in children. Acta paedif. Scand., 58, 157-163.

Sterner, G. (1962). Adenovirus infection in childhood. Acta paedi⿳亠丷⿵冂. (Uppsala), Suppl., 142.

Strang, C. (1956). The fate of children with bronchiectasis. Ann. inte $\overline{\text { Tit. }}$. Med., 44, 630-656.

Swierenga, J. (1957). Childhood bronchiectasis. Dis. Chest, 32, 134 161 .

Van der Veen, J., and Dijkman, J. H. (1962). Association of typo adenovirus with acute respiratory illness in military recruits Amer. J. Hyg., 76, 149-159. 